\title{
Aerosol kinetics and bronchodilator efficacy during continuous positive airway pressure delivered by face mask
}

\author{
Scott N Parkes, Andrew D Bersten
}

\begin{abstract}
Background - Rates of fresh gas flow (FGF) commonly used when continuous positive airway pressure (CPAP) is delivered by face mask theoretically reduce the delivery and availability of therapeutic aerosols. As it may be hazardous for patients with acute respiratory failure to interrupt mask CPAP, the effects of CPAP on aerosol kinetics and bronchodilator efficacy were investigated.
\end{abstract}

Method - The effect of CPAP at $10 \mathrm{~cm} \mathrm{H}_{2} \mathrm{O}$ at a FGF rate of $501 / \mathrm{min}$ on the delivery of technetium labelled aerosol generated from a readily available jet nebuliser was measured using a bench model of spontaneous respiration. In a separate clinical study the bronchodilator responses to incremental doses of nebulised salbutamol were measured in nine stable asthmatic subjects in a random sequence of conventional nebulisation (control) or nebulisation whilst receiving CPAP via a tight fitting face mask. Each patient acted as his or her own control.

Results - CPAP significantly reduced total aerosol delivery to the face mask from $6.85(1.52) \%$ to $1.3(0.37) \%$ of the initial nebuliser charge. In the clinical study a significant bronchodilator response to nebulised salbutamol was seen during both conventional nebulisation and nebulisation whilst receiving CPAP by face mask. The shape of the dose-response curves and the magnitude of the total increase in the forced expiratory volume in one second $\left(\mathrm{FEV}_{1}\right)$ was identical for CPAP and control conditions.

Conclusions - Despite a reduction in aerosol presented to the proximal airway, the bronchodilator response to inhaled $\beta_{2}$ agonists in stable asthmatic subjects was not affected when CPAP was delivered by face mask. Despite a high rate of FGF, nebulised $\beta_{2}$ agonists are effective when administered in conjunction with CPAP delivered by face mask.

(Thorax 1997;52:171-175)

Keywords: positive pressure respiration, bronchodilator, aerosols.

Continuous positive airway pressure (CPAP) is widely used in the management of patients with severe acute respiratory failure. In patients with severe cardiogenic pulmonary oedema we found that CPAP delivered by face mask hastened recovery and prevented the need for intubation and mechanical ventilation. ${ }^{1}$ In a group of patients with dynamic hyperinflation and intrinsic positive end expiratory pressure (PEEP) Petrof and co-workers ${ }^{2}$ found that the application of CPAP to intubated patients significantly reduced respiratory work. It seems likely that non-invasive CPAP will produce a similar benefit in patients with acute severe asthma or acute exacerbations of chronic airflow obstruction. However, therapeutic aerosols are central to the management of these patients, and the concurrent administration of CPAP may interfere with drug delivery to the distal airway.

Mask CPAP is optimally applied through a continuous fresh gas flow (FGF) circuit as this imposes less additional work than a demand valve system ${ }^{34}$ and compensates more efficiently for potential gas leaks around the mask. Despite the use of a six litre compressed reservoir bag, we found that an FGF rate approaching the patient's peak inspiratory flow rate is needed to minimise the additional work imposed by a continuous gas flow CPAP circuit. $^{5}$ As critically ill patients often have high inspiratory flow rates, high rates of FGF are required to maintain circuit efficiency.

Therapeutic aerosols may be administered concurrently with CPAP or during its interruption. As the effects of CPAP on respiratory mechanics are rapidly lost when it is stopped, ${ }^{6}$ it is preferable to administer aerosols concurrently with CPAP. However, aerosols are physically unstable systems consisting of droplet and vapour phases, and their entrainment into the high rates of FGF used with CPAP may dilute the aerosol and reduce the number of aerosol particles due to impaction within the apparatus. In addition, high rates of FGF will favour evaporation within the aerosol leading to cooling and hypertonicity of the aerosol droplets, ${ }^{7}$ with the potential to produce paradoxical bronchoconstriction.

Recent studies ${ }^{8-10}$ have focused on aerosol delivery during conventional mechanical ventilation. The conditions during non-invasive CPAP differ as a face mask replaces the endotracheal tube, a continuous rather than demand flow system is used, and aerosol is generated during both inspiration and expiration. Thus, these results are not directly applicable to patients receiving CPAP by face mask. We therefore sought to measure the effects of continuous gas flow CPAP on total aerosol delivery (using a bench model) and on the bronchodilator response to a nebulised $\beta_{2}$ agonist. 


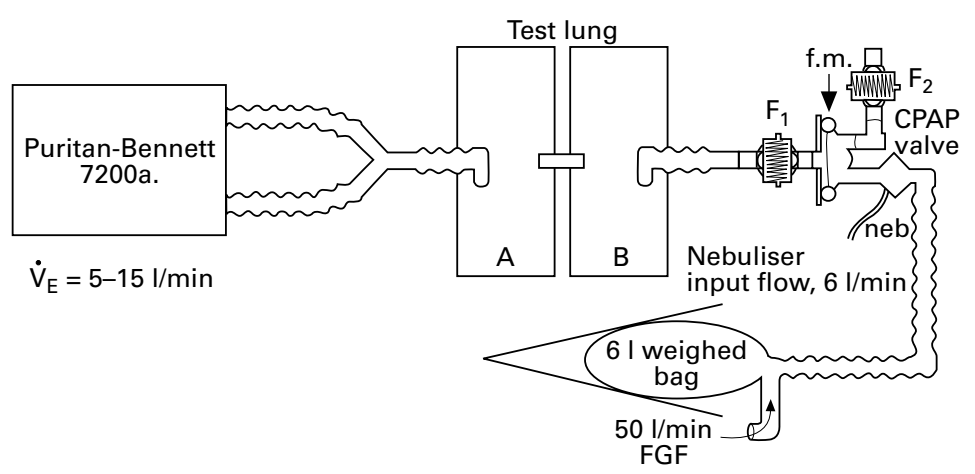

Figure 1 Experimental apparatus used in bench studies of aerosol delivery. $\dot{V}_{E}=$ minute ventilation, neb=nebuliser, f.m. $=$ face mask, $F_{1}$ and $F_{2}=$ filters placed as absolute aerosol traps. mediately proximal to the mask and the FGF and nebuliser driving gases were compressed wall gas with no external humidification.

During CPAP conditions a disposable hydrophobic filter (Pall, No. BB22-15, Portsmouth, UK) was used as an absolute aerosol trap ${ }^{16}$ and placed immediately distal to the face mask $\left(\mathrm{F}_{1}\right.$, fig 1). Activity deposited on this filter was measured as an estimate of the proportion of aerosol available for respiration by the simulated patient and was expressed as a percentage of the initial nebuliser charge (inhaled aerosol \%). A second filter $\left(F_{2}\right.$, fig 1$)$ was placed on the expiratory limb of the CPAP valve to estimate the proportion of the aerosol wasted through the valve. Nebuliser residual activity was measured by counts taken after nebulisation was complete. Aerosol impaction in the mask and CPAP valve was estimated by subtraction of the inhaled aerosol activity and residual activity from the initial nebuliser charge and expressed as its percentage (apparatus aerosol \%). During control conditions of unassisted spontaneous ventilation filters were placed at the face mask as before and at the non-patient end of the nebuliser. Gas temperature was measured at the face mask with a K-type thermocouple and a digital thermometer (model 52, Fluke Instruments, Illinois, USA). Gamma activity was measured by a Searle Radiographics radioisotope calibrator (model CRC-22NB) and a Berthoid radiation monitor (model CB 1210D). varied to produce minute volumes of $2.5,5.0$, $7.5,10.0$, and $15.01 / \mathrm{min}$ or while minute volume was kept constant at $10 \mathrm{l} / \mathrm{min}$ and tidal volume was varied at 250,500 , and $1000 \mathrm{ml}$. An approximately $90 \%$ square flow pattern was used because it is typical of critically ill patients. ${ }^{13-15}$

The compartment simulating the lungs was then connected in turn via a standard right angled connector to a face mask (Vital Signs, Totowa, New Jersey, USA) strapped onto a tight fitting board and orifice, and to a modified Mapleson-A CPAP circuit $^{5}$ (representing the circuit and mask applied to the face). Briefly, this consists of corrugated tubing ( 1.5 metres long and $19 \mathrm{~mm}$ internal diameter) and a six litre reservoir bag (Warne Franklin, High Wycombe, Buckinghamshire, UK) compressed by a weighted hinged board, driven by FGF at a rate of $50 \mathrm{l} / \mathrm{min}$. This rate of gas flow was chosen as it is in the mid range of inspiratory flow rates of patients treated with mask CPAP in our intensive care unit. For the CPAP experiments a $10 \mathrm{~cm} \mathrm{H}_{2} \mathrm{O}$ valve (Vital Signs) was applied to the mask, and for the control experiments the mask was open to room air (that is, no CPAP circuit was attached).

At each pattern of ventilation the deposition of radioaerosol was determined four times under both CPAP and control conditions. In each experiment a nebuliser (Bird Micronebuliser P/No. 158, Bird, California, USA) was filled with a measured activity (approximately $50 \mu \mathrm{Ci}$ ) of technetium pertechnetate in $3 \mathrm{ml}$ physiological saline (nebuliser charge) and nebulised to its residual volume using an input flow of $6 \mathrm{l} / \mathrm{min}$. In each experiment the nebuliser was placed im-

\section{BRONCHODILATOR STUDIES \\ Subjects}

Ten subjects with chronic stable asthma and a previously demonstrated increase in forced expiratory volume in one second $\left(\mathrm{FEV}_{1}\right)$ of at least $15 \%$ after nebulised $\beta_{2}$ agonist were studied. All subjects gave written informed consent prior to commencing the investigation and the studies were approved by the hospital's Committee on Clinical Investigation.

\section{Study design}

Subjects were studied in a predetermined randomised sequence of CPAP and control on two successive days at the same time of day. Inhaled prior to each study period and the morning dose of oral theophylline (three subjects) was not given until after each study period. Inhaled and oral corticosteroid therapy was continued unchanged.

On arrival subjects rested for 10 minutes before measurement of their $\mathrm{FEV}_{1}$ with a Vitalograph spirometer. On the day CPAP was given the subject next received face mask CPAP at $10 \mathrm{~cm} \mathrm{H}_{2} \mathrm{O}$ using a $50 \mathrm{l} / \mathrm{min} \mathrm{FGF}$ and the $\mathrm{FEV}_{1}$ was again measured. Subjects then received nebulised salbutamol (salbutamol 5\% aqueous solution, Allen and Hanburys, Victoria, Australia) concurrently with CPAP in incremental doses of $250 \mu \mathrm{g}, 250 \mu \mathrm{g}, 500 \mu \mathrm{g}$, and $1000 \mu \mathrm{g}$ at 30 minute intervals to produce a sequential doubling in cumulative dose (total cumulative dose $2000 \mu \mathrm{g}) .{ }^{17}$ Each dose was $\beta_{2}$ agonist was withheld for at least six hours 


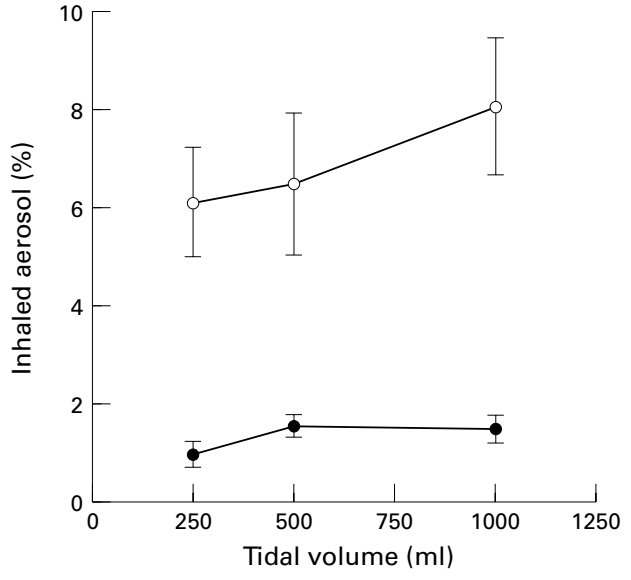

Figure 2 Influence of tidal volume on aerosol availability to the simulated patient airway (expressed as a fraction of the nebulised dose of isotope) at a constant minute volume of $10 \mathrm{l} / \mathrm{min} ; \bigcirc=$ unassisted spontaneous ventilation; $\mathbf{O}=$ continuous positive airway pressure. Data are mean (SD).

diluted to a final volume of $3.0 \mathrm{ml}$ with physiological saline and nebulised to chamber residual volume. $\mathrm{FEV}_{1}$ was measured five and $30 \mathrm{~min}$ utes after completion of each dose. On the control day salbutamol was administered through the same face mask and nebuliser but without the CPAP valve or FGF attached. All measurements of $\mathrm{FEV}_{1}$ were taken as the best of three maximum forced exhalations \pm 0.05 litres and were recorded with the face mask and CPAP circuit removed.

STATISTICAL ANALYSIS

Radioisotope aerosol deposition was analysed using the Student's $t$ test for paired data. The analysis of dose and $\mathrm{FEV}_{1}$ relationships used repeated measures ANOVA. All numerical values are expressed as mean (SD) unless otherwise stated, and gas volumes are expressed on the ATPS scale.

\section{Results}

BENCH STUDIES

Aerosol deposition

At a constant minute volume of $101 / \mathrm{min}$ inhaled aerosol \% was independent of tidal volume and averaged for statistical comparison (fig 2). CPAP was associated with a reduction in inhaled aerosol \% from $6.85(1.52) \%$ under control conditions to $1.3(0.37) \%$ on CPAP $(p<0.01)$. Correspondingly, the rate of FGF when on CPAP was associated with an increase in apparatus aerosol \% from $13.9(8.2) \%$ under control conditions to 40.1 (7.6)\% on CPAP.

As minute ventilation increased (tidal volume constant at $500 \mathrm{ml}$ ), inhaled aerosol \% increased to a maximum at approximately $10 \mathrm{l} /$ min. This effect was not seen during CPAP (fig 3).

Gas temperature

Gas temperature at the face mask fell more rapidly during concurrent nebulisation with

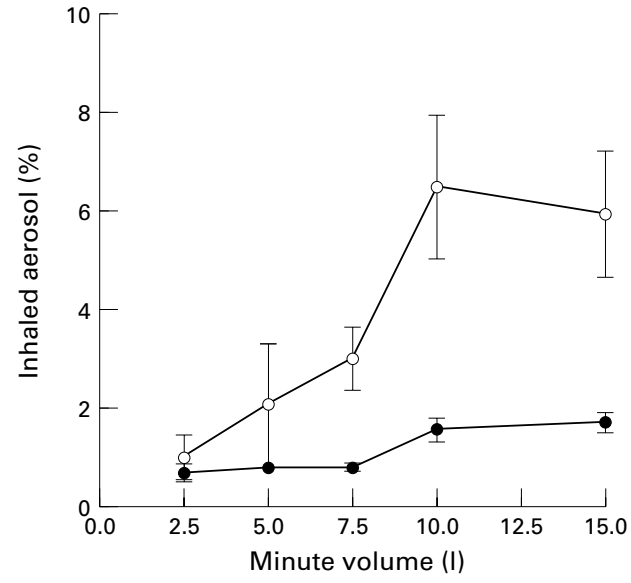

Figure 3 Influence of minute volume on aerosol availability to the simulated patient airway (expressed as a fraction of the nebulised dose of isotope) at a constant tidal volume of $500 \mathrm{ml} ; \bigcirc=$ unassisted spontaneous ventilation; =continuous positive airway pressure. Data are mean $(S D)$.

CPAP. The minimum temperature during CPAP was $10.0(0.1)^{\circ} \mathrm{C}$ compared with 15.1 $(0.4)^{\circ} \mathrm{C}$ during control conditions (fig 4).

\section{BRONCHODILATOR STUDIES}

Patient characteristics

Of the 10 subjects studied, one was excluded because of a fall in $\mathrm{FEV}_{1}$ of $60 \%$ with serial maximal expiratory spirometry (this met a predetermined withdrawal criterion). The remaining nine subjects (five men) of mean age 45 years (range 27-69) completed both days of the study. Eight subjects received inhaled budesonide (mean dose $3 \mathrm{mg}$ per day; range $1.6-3.6 \mathrm{mg}$ ), and one received oral prednisolone $(10 \mathrm{mg} /$ day). All drug doses had been stable for four weeks before the study period. Four subjects received salbutamol through the CPAP circuit on day 1.

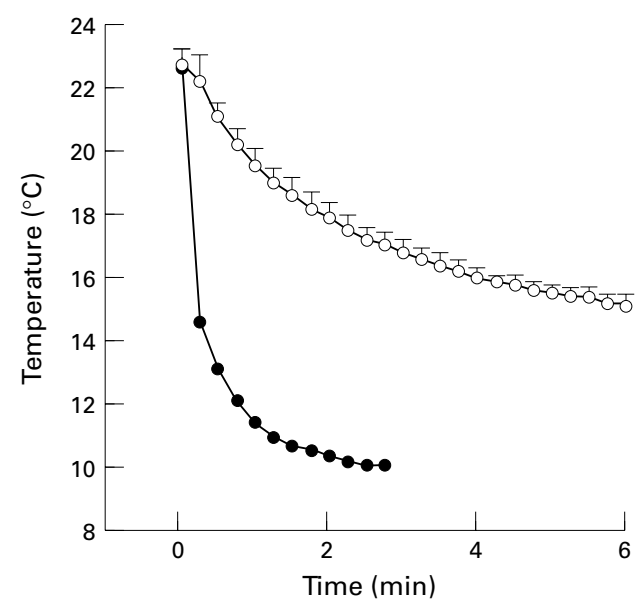

Figure 4 Aerosol temperature at the simulated patient airway at a minute volume of $10 \mathrm{l} / \mathrm{min}$ and a tidal volume of $500 \mathrm{ml} ; \bigcirc=$ unassisted spontaneous ventilation; $\mathbf{O}=$ continuous positive airway pressure. Data are mean (SD). 


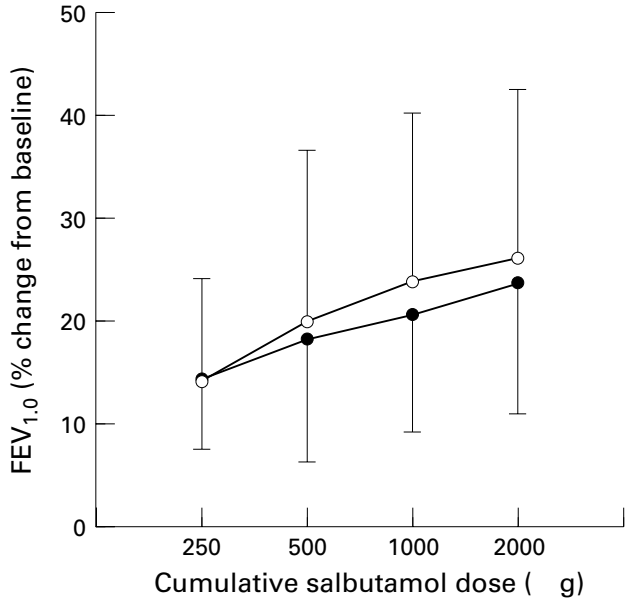

Figure 5 Cumulative salbutamol dose-response curve $(n=9)$ during spontaneous ventilation (O) and continuous positive airway pressure (). Data are mean $(S D)$.

Baseline spirometric values

There was no difference in prebronchodilator $\mathrm{FEV}_{1}$ on the CPAP (2.3(0.8) 1) or control $(2.3(0.9) 1)$ days of the study. The interval between the subject's last dose of salbutamol and the commencement of the study period was the same on each day (CPAP day, 7.9 (4.6) hours; control, 8.2 (4.4) hours). There was no difference in $\mathrm{FEV}_{1}$ before $(2.3(0.8)$ l) and after $(2.3(0.7) 1)$ the application of CPAP alone without bronchodilator.

\section{Bronchodilator responses}

The dose-response curves for salbutamol are shown in fig 5. A log linear relationship was seen between cumulative dose and increase in $\mathrm{FEV}_{1}$ above baseline. The magnitude of the increase and the slope of the curves were identical for CPAP (0.0049 (0.0031)) and control $(0.0060(0.0034))$ conditions $(p=0.46)$. The mean difference in slope between control and CPAP conditions was $0.0012(0.0047)$ with $95 \%$ confidence intervals of -0.0047 to 0.0024 . The maximum increase in $\mathrm{FEV}_{1}$ with a cumulative dose of $2.0 \mathrm{mg}$ was 23.7 (12.8)\% during concurrent administration with CPAP and 26.1 (16.5)\% during control conditions, with a mean difference of $-2.4(13.4) \%(\mathrm{p}=$ 0.74 ) and $95 \%$ confidence intervals of -12.7 to 8.0 .

\section{Discussion}

In a bench model of spontaneous respiration this study has shown that CPAP induced significant changes in aerosol characteristics. Inhaled aerosol \% was reduced fivefold during CPAP and became independent of minute ventilation. These findings suggest that conditions unique to FGF mask CPAP are more important than minute ventilation and respiratory pattern as determinants of total inhaled aerosol. In addition, CPAP was associated with a greater fall in aerosol and gas temperature during nebulisation. Both the reduction in in- haled aerosol $\%$ and the fall in gas temperature found in our bench studies will favour reduced bronchodilator efficacy.

In a cohort of stable asthmatic subjects the bronchodilator response to nebulised salbutamol was not affected when the aerosol was administered via a CPAP circuit and tight fitting face mask. Caution must be exercised in extrapolating our data to critically ill patients with acute respiratory failure. In contrast to stable asthmatic subjects, patients with acute respiratory failure are likely to have higher inspiratory flow rates and smaller tidal volumes, ${ }^{14}$ and it is known that this ventilatory pattern is associated with reduced bronchodilator aerosol delivery to the peripheral airways. ${ }^{18}$ However, it is important to recognise that these considerations will apply equally whether salbutamol is administered by conventional nebulisation or via a CPAP circuit. Further, in patients with acute respiratory failure CPAP may favour bronchodilator aerosol delivery to the peripheral airways by reducing both the degree of tachypnoea and inspiratory flow rate.

In the cohort of stable asthmatic subjects progressive submaximal responses were seen to incremental doses of salbutamol, and the resultant dose-response curves were identical for both CPAP and control conditions. Thus, during stable asthma, delivery of $\beta_{2}$ agonist to its parent receptor was not altered by CPAP. For these reasons we believe it is appropriate to extend these findings to patients with airflow obstruction during acute respiratory failure and it is now our practice to administer $\beta_{2}$ agonist concurrently with CPAP in these patients. We used non-humidified compressed gas in both the clinical and bench experiments to maximise the temperature and osmolar changes that occur when the aerosol is entrained into the fresh gas flow. Furthermore, as it is our experience that many acutely breathless patients are unable to tolerate heating and humidification of the circuit because of a sensation of suffocation, we do not humidify the circuit during the short term (less than four hours) administration of CPAP.

Our data suggest that continuous gas flow CPAP delivered by face mask reduces total aerosol delivery without affecting the bronchodilator efficacy of nebulised $\beta_{2}$ agonists. The application of CPAP to both normal subjects ${ }^{19}$ and subjects with induced asthma ${ }^{6}$ increases minute ventilation by around $50 \%$. We did not measure minute ventilation during the clinical study, but used a bench model of spontaneous respiration to allow accurate reproducible breathing patterns as minute volume was varied between 2.5 and $15 \mathrm{l} / \mathrm{min}$. These values were chosen to include the likely range of minute ventilation in critically ill patients. From an examination of the effect of increasing minute volume on aerosol delivery during CPAP (fig 3 ), the consequent increase in drug reaching the proximal airway as minute ventilation is increased is far too small to explain the apparently paradoxical finding of a similar bronchodilator response to salbutamol during its concurrent administration with CPAP. 
In subjects with induced asthma CPAP is associated with an increase in end expiratory lung volume. However, this effect is small and diminishes after several breaths. ${ }^{6}$ While increases in lung volume may alter aerosol delivery because of alterations in airway geometry, this effect is likely to be small.

The distribution of particle size of an aerosol is known to be a major determinant of aerosol penetrance and its regional aerosol deposition within the lung. In our study nebulised $\beta_{2}$ agonist was entrained into a non-humidified gas flow of $50 \mathrm{l} / \mathrm{min}$. The resultant turbulence is likely to favour impaction of larger, and therefore less respirable, particles within the apparatus in comparison with smaller particles. ${ }^{20}$ This is supported by the observation of increased aerosol deposition within the face mask, an effect likely to be due to turbulence. In addition, movement of water molecules from the liquid to the vapour phase of the aerosol will occur with a non-humidified fresh gas flow, also contributing to a reduction in particle size. Our finding of an accentuated fall in aerosol temperature with mask CPAP suggests this may have been a significant process. However, we did not perform direct measurements of aerosol particle size, and specific studies would be needed to confirm this.

When CPAP is used as supportive therapy in patients with acute respiratory failure, spontaneous ventilation through an unprotected airway is maintained at a time when there are major adverse changes in pulmonary mechanics and gas exchange. For this reason these patients are often in a more precarious clinical situation than those who are treated by conventional mechanical ventilation, and a successful outcome may require more rapid treatment of the underlying causes of the respiratory failure. Bronchodilator aerosols may be central to management of these patients, and the demonstration that bronchodilator efficacy is maintained during CPAP is an important finding.

At a circuit FGF rate of $501 /$ min the bronchodilator efficacy of $\beta_{2}$ agonist is maintained when nebulisation proceeds concurrently with CPAP, and this study suggests that it is appropriate to administer $\beta_{2}$ agonist in this fashion. However, as ipratropium bromide, which has an additive bronchodilator effect, ${ }^{2122}$ acts on more centrally situated receptors, it is possible that its biological effect is altered by concurrent CPAP and studies specific to this agent are required. The precise mechanism by which the bronchodilator response to nebulised $\beta_{2}$ agonist is maintained despite a significant reduction in total aerosol availability also warrants further investigation.

We would like to thank Dr John Plummer for his expert help with statistical analysis and $\mathrm{Mr}$ Charles Evill for his assistance with measurement of isotope activity.

1 Bersten AD, Holt AW, Vedig AE, Skowronski GA, Baggoley CJ. Treatment of severe cardiogenic pulmonary edema CJ. Treatment of severe cardiogenic pulmonary edema
with continuous positive airway pressure delivered by face with continuous positive airway pressure
mask. $N$ Engl $\mathcal{F}$ Med 1991;325:1825-30.

2 Petrof BJ, Legare M, Goldberg P, Milic-Emili J, Gottfried SB. Continuous positive airway pressure reduces work of breathing during weaning from mechanical ventilation in severe chronic obstructive pulmonary disease. Am Rev Respir Dis 1990;141:281-9.

3 Katz JA, Kraemer RW, Gjerde GE. Inspiratory work and airway pressure with continuous positive airway pressure delivery systems. Chest $1985 ; \mathbf{8 8}: 519-26$.

4 Gibney RTN, Wilson RS, Pontoppidan H. Comparison of work of breathing of high gas flow and demand valve continuous positive airway pressure systems. Chest 1982 82:692-5.

5 Bersten AD, Rutten AJ, Vedig AE. Optimising fresh gas flow and circuit design for the delivery of continuous
positive airway pressure. Crit Care Med 1991;19:226-70.

positive airway pressure. Crit Care Med 1991;19:226-70.
6 Martin J, Shore S, Engel J. Effect of continuous positive airway pressure on respiratory mechanics and pattern of airway pressure on respiratory mechanics and pattern of
breathing in induced asthma. Am Rev Respir Dis 1982; 126:812-7.

7 Phipps P, Gonda I. Droplets produced by medical nebulisers. Some factors affecting their size and solute concentration. Chest 1990;97:1327-32

8 Thomas SH, O'Doherty MJ, Fidler HM, Page CJ, Treacher DF, Nunnan TO. Pulmonary deposition of a nebulised aerosol during mechanical ventilation. Thorax 1993;48 $154-9$

9 O’Riordan T, Greco M, Perry R, Smalldone G. Nebuliser function during mechanical ventilation. Am Rev Respir Dis 1992;145:1117-22.

10 O'Doherty M, Thomas S, Page C, Treacher D, Nunnan T. Delivery of a nebulised aerosol to a lung model during mechanical ventilation. Am Rev Respir Dis 1992;146:383-

11 Katz JA, Kramer RW, Gjerde GE. Inspiratory work and airway pressure with continuous positive airway pressure airway pressure with continuous positiv
delivery systems. Chest $1985 ; \mathbf{8 8}: 519$.

12 Bersten AD, Rutten AJ, Vedig AE. Additional work of breathing imposed by endotracheal tubes, breathing cirbreathing imposed by endotracheal tubes, breathing circuits and

13 McIlroy MB, Christie RV. The work of breathing in emphysema. $\mathcal{F}$ Clin Invest 1954;33:157.

14 LaFortuna CL, Minetti AE, Mognoni P. Inspiratory flow patterns in humans. F Appl Physiol 1984;57:1111-9.

15 Sharp JT, Griffith GT, Bunnell IL. Ventilatory mechanic in pulmonary edema in man. $\mathcal{F}$ Clin Invest $1958 ; 37: 111$

16 Duberstein R, Howard D. Sterile filtration of gases: a bacteriologic challenge test. $\mathcal{F}$ Parenter Drug Assoc 1978;32:4

17 Johnson M, Newman ST, Bloom R. Delivery of albutero and ipratropium from two nebuliser systems in chronic and ipratropium from two nebulis

18 Newhouse MT, Dolovich MB. Control of asthma by aerosols. N Engl f Med 1986;315:870-3.

19 Bishop B, Hirsch J, Thirby M. Volume, flow, and timing of each breath during positive pressure breathing in man. $f$ Appl Physiol (Respirat Environ Exercise) 1978;45:495-501.

20 Mercer TT. Production of therapeutic aerosols. Principles and techniques. Chest 1981;80(S):813-8.

21 Higgins RM, Straddling JR, Lane DJ. Should ipratropium Higgins RM, Stradding JR, Lane DJ. Should ipratropium
bromide be added to beta agonists in the treatment of bromide be added to beta agonists in the
acute severe asthma? Chest 1988;94:718-22

22 Braun SR, Levy SF, Grossman J. Comparison of ipratropium and albuterol in chronic obstructive pulmonary disease: a three centre study. Am f Med 1991;91(Suppl 4A):28-32S. 